\title{
Appearance and number of follicles and change in the concentration of serum FSH in female bovine fetuses
}

\author{
Y. Tanaka, K. Nakada*, M. Moriyoshi and Y. Sawamukai \\ Department of Veterinary Obstetrics and Gynecology, Rakuno Gakuen University, 582-1 \\ Bunkyodai-Midorimachi, Ebetsu, Hokkaido 069-8501, Japan
}

The aim of this study was to determine the relationships between early follicular development, the time at which follicles appear in early stages of follicular development, and changes in the serum concentrations of $\mathrm{FSH}$ in the female bovine fetus. Thirty-five female bovine fetuses aged between 59 and 285 days, as estimated from the crown-rump length, were obtained from dams at an abattoir. Serum samples were separated from fetal blood obtained from the heart. Fetal ovaries were removed and weighed. The content of oestradiol in one of the fetal ovaries and the serum concentrations of FSH and oestradiol were determined using radioimmunoassay. Sections of the other ovary were examined histologically for the appearance and number of follicles. The follicles were divided into four stages: primordial, primary, secondary and early antral. The appearance of primordial, primary, secondary and early antral follicles was observed at day 74, day 91, day 120 and day 150, respectively. Serum concentrations of FSH in female bovine fetuses increased between day 120 and day 150 of gestation. Fetal serum concentrations of oestradiol increased from day 120. The number of early antral follicles increased from day 180 together with an increase in the fetal ovarian content of oestradiol. These findings indicate that, in the female bovine fetus as well as in adult cows, the number of follicles and stages of follicular development are associated with changes in the concentration of FSH.

\section{Introduction}

Folliculogenesis in various animals has been examined both in vitro and in vivo in many laboratories. It has been reported that $\mathrm{FSH}$ affects the development of secondary follicles to dominant follicles in the ovaries of adult mammals (Erickson and Danforth, 1995). FSH stimulates the activation of aromatase and accelerates the production of oestrogen (Bao et al., 1997). The proliferation of granulosa cells in the follicle is enhanced by an autocrine action of oestrogen, which is stimulated by FSH (Peters and McNatty, 1980).

Bao and Garverick (1998) reported that FSH plays an important role in the recruitment of some early antral follicles in the ovary of adult cows. In addition, a few antral follicles are selected by an increase in the frequency of the LH pulse, and they develop into dominant follicles, and subsequently ovulate. Insulin-like growth factor I, growth differentiation factor 9, vasoactive intestinal polypeptide and FSH may affect the development of primordial and primary follicles, although the main initiator responsible for development of primordial follicles to secondary follicles is unknown (George and Ojeda, 1987; Erickson and Danforth, 1995).

*Correspondence

Email: kenn@rakuno.ac.jp
Erickson (1966) reported that follicles are already present in the bovine fetus during the early stages of gestation. Rüsse (1983) reported that primordial, primary and secondary follicles appeared at day 90, day 140 and day 210 of gestation, respectively, in the bovine fetus. McNatty et al. (1995) also observed the appearances of follicles at different stages of development in the ovary of sheep follicles with advancing fetal age: primordial, primary, secondary and early antral follicles appeared at day 75, day 100, day 120 and day 135 of fetal age, respectively. Sklar et al. (1981) and Mueller et al. (1981) observed that serum FSH concentrations increased from day 90 to day 120 in the female ovine fetus. Limited data indicated that in the ovine fetus, the oestradiol concentration in the circulation increased after day 100 (Findlay and Seamark, 1973). Development of the follicles in the fetal ovary may be dependent on $\mathrm{FSH}$, and the follicles responsive to $\mathrm{FSH}$ may produce oestrogen. However, in the female bovine fetus, there have been no reports on either the serum concentration of $\mathrm{FSH}$ or the appearance of follicles in the early stages of gestation. Therefore, the aim of the present study was to determine the relationship between the appearance of follicles in the early stages of gestation and the serum concentration of $\mathrm{FSH}$ in the female bovine fetus. The relationships among the presence of follicles in the fetal ovary, serum concentrations of oestradiol and ovarian content of oestradiol in the bovine fetus were also investigated. 


\section{Materials and Methods}

\section{Fetuses}

Uteri were collected from 94 pregnant Holstein-Friesian cows immediately after the animals were killed. Fetal age was estimated from the crown-rump length (CRL) according to the methods described by Evans and Sack (1973). The sex of the fetus was determined on the basis of external genitalia and was confirmed by visualization of fetal gonads under a light microscope. Thirty-five of 94 fetuses were female, and ranged in age from 59 to 285 days.

\section{Serum samples}

Fetal blood, obtained from the heart using a syringe, was centrifuged at $1700 \mathrm{~g}$ for $15 \mathrm{~min}$ and the serum obtained as the supernatant was stored at $-30^{\circ} \mathrm{C}$ until assayed for $\mathrm{FSH}$ and oestradiol.

\section{Gonads}

Both ovaries were removed from each fetus and weighed. One of the ovaries was homogenized with $1 \mathrm{ml}$ saline and stored at $-30^{\circ} \mathrm{C}$ until assayed for oestradiol. The other ovary was cut along the long axis and fixed immediately in $4 \%(\mathrm{w} / \mathrm{v})$ paraformaldehyde in $0.01 \mathrm{~mol}$ PBS I-1, pH 7.4, and embedded in paraffin wax. The ovary embedded in paraffin wax was cut into serial sections of $5 \mu \mathrm{m}$ in thickness and mounted on silane-coated slides. The slides were stained with haematoxylin-eosin and examined by light microscopy.

\section{Classification of follicles}

The follicles observed were classified into four groups: (i) primordial follicles (oocytes encompassed by germ epithelial cells (pre-granulosa cells)); (ii) primary follicles (oocytes encompassed by one layer of cubic or columnar granulosa cells with no theca cells); (iii) secondary follicles (oocytes encompassed by two or more layers of granulosa and theca cells); and (iv) early antral follicles (oocytes encompassed by multiple layers of granulosa and theca cells, and including antra).

\section{Determination of the number of follicles}

The average number of follicles in five sections of the ovary $(C f)$, which was cut around the centre along the long axis, was counted as the total number of all follicles at each stage in an ovarian section. The volume of the ovary (Vo) was calculated using half of the long axis $(\mu \mathrm{m} ; \mathrm{a})$ and half of short axis $(\mu \mathrm{m} ; b)$ of the ovary. The volume of the section $(V s)$ was calculated using the long and short axis, and the thickness of a section $(5 \mu \mathrm{m})$. The thickness of the ovary $(\mu \mathrm{m} ; c)$ and the maximum diameter of the follicles $(D f)$ in the each section were measured to correct the number. The number of follicles $(N f)$ was determined using the following formulae:

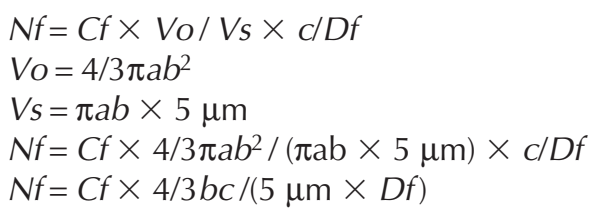

\section{Radioimmunoassay of FSH and oestradiol}

Serum concentrations of FSH were determined by radioimmunoassay with rabbit antiserum against bovine FSH $\beta$-subunit (USDA-5), USDA-bFSH-I-2 radioiodinated and USDA-bFSH-I-2 as a reference standard (modified from Bolt and Rollins, 1988). The sensitivity of the assay for FSH was 0.98 pg per tube. The intra- and interassay coefficients of variation were 4.9 and $12.2 \%$, respectively.

Serum and ovarian concentrations of oestradiol were determined by radioimmunoassay, as described by Taya et al. (1985), with ovine antiserum against oestradiol (GDN244; Korenman et al., 1974) and 125I-labelled oestradiol (IM135, oestradiol-6(O-carboxymethyl)oximino(2-[125I]iodohistamine); Amersham, les Ulis). Before the assay was performed, serum and homogenized samples were prepared by extracting oestradiol with diethyl ether, and defatting with acetonitrile and $n$-hexane. The sensitivity of the assay for oestradiol was $0.16 \mathrm{pg}$ per tube. The intraand interassay coefficients of variation were 2.3 and $8.6 \%$, respectively.

\section{Statistical analysis}

All values are presented as means \pm SEM. The quantitative data obtained from the radioimmunoassay measurements were compared between two groups of fetal samples using the Student's $t$ test and among three or more groups using Duncan's multiple-range test. Correlations between fetal serum concentration and ovarian contents were assessed using Bartlett's test and Fisher's z conversion of $r$.

\section{Results}

\section{Changes in ovarian mass}

The mass of one ovary from the bovine fetus increased with respect to gestational age (Fig. 1). Ovarian mass increased from $12 \mathrm{mg}$ (day 59) to $98 \mathrm{mg}$ (day 118). Between day 120 and day 177 ovarian mass did not change significantly $(76.9 \pm 7.6 \mathrm{mg})$, but there was a marked increase from $102 \mathrm{mg}$ to $553 \mathrm{mg}$ between day 180 and day 285.

\section{Number of follicles and germ cells}

At day 91, the number of germ cells in fetal ovaries reached a peak (2770 880; Fig. 2). After 91 days, the number of germ cells decreased to 38080 at day 160 and to 16200 at day 285. Primordial follicles appeared in the cortex layer at day 74 , and the number of these follicles increased up to day 120 (Fig. 3), but did not change 


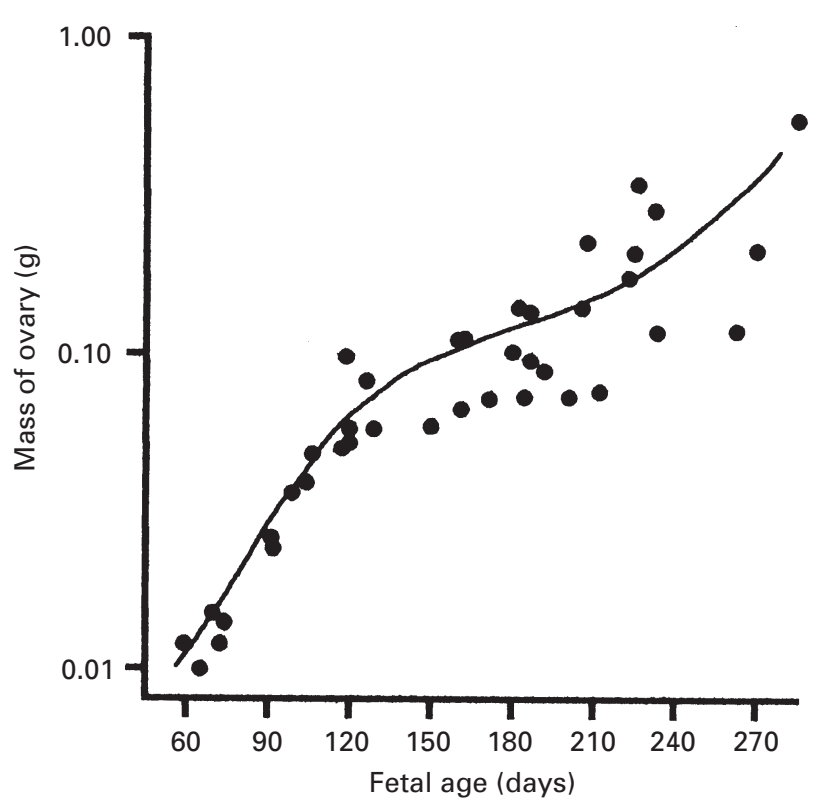

Fig. 1. The changes in ovarian mass (g) with respect to gestation in the bovine fetus $(n=37)$.

markedly from day 120 to day 285 (8233.6 \pm 1662.8; means \pm SEM). Primary follicles appeared in the deep cortex layer at day 91, but the number of these follicles did not change markedly from day 150 to day 285 (3253.7 \pm 486.2$)$. Blood capillaries were observed around the primary follicles. Secondary follicles appeared in the superficial medulla layer at day 120 . The number of these follicles increased up to day 150 and remained at $496.2 \pm 82.0$ from day 150 to day 285. A few venules and some capillaries were observed around the secondary follicles, and were particularly apparent after day 160 . Early antral follicles appeared in the deep medulla layer at day 150 , and the number of these follicles increased from day 180 to day 285 . One vesicular follicle (diameter of $1.2 \mathrm{~mm}$ ) was observed in a fetal ovary after day 233.

\section{Serum concentration of FSH}

The serum concentration of FSH was $3.0 \pm 0.1 \mathrm{pg} \mathrm{ml}^{-1}$ from day 59 to day 117, when germ cells, oocytes and primordial follicles were observed by light microscopy (Fig. 4). Serum FSH started to increase after day 120 (50.7 $\mathrm{pg} \mathrm{ml}^{-1}$ ), when secondary follicles appeared and started to increase in number. The serum concentration of FSH was $60.4 \pm 8.5$ pg ml-1 from day 118 to day 149 and increased up to day 159 (265.9 $\left.\mathrm{pg} \mathrm{ml}^{-1}\right)$. The concentration of $\mathrm{FSH}$ was $218.9 \pm 50.2 \mathrm{pg} \mathrm{ml}^{-1}$ from day 150 to day 185 , before the number of early antral follicles started to increase. The concentration of FSH decreased to $139.2 \pm 20.4 \mathrm{pg} \mathrm{ml}^{-1}$ from day 186 to day 285 , when the number of these follicles in the medulla started increasing. The serum concentration of FSH between day 120 and day 150 was significantly higher than that between day 65 and day $118(P<0.05)$, (a)

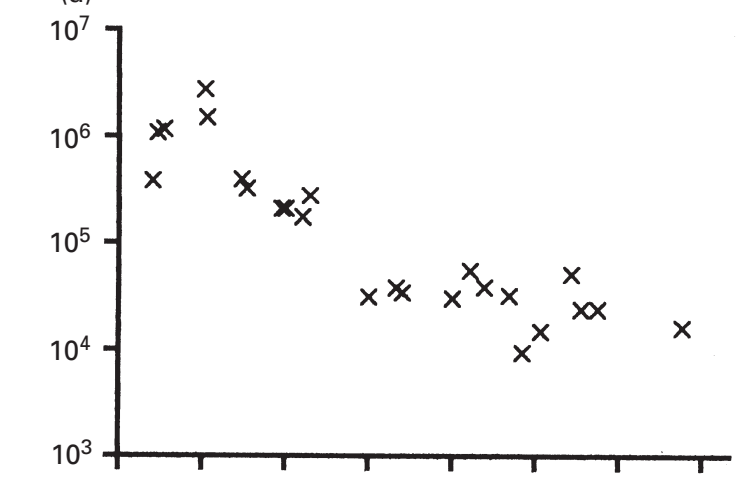

(b)
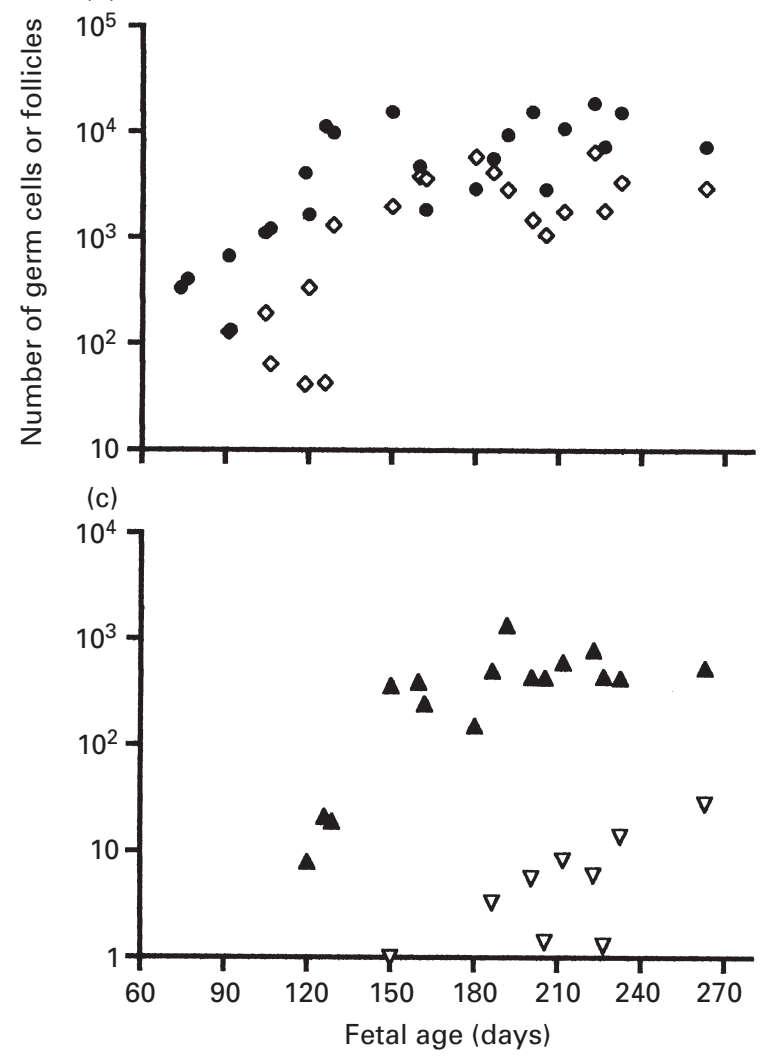

Fig. 2. Changes in the number of follicles and germ cells in bovine fetal ovaries $(n=25)$ with increasing fetal age. (a) Germ cells $(X)$, (b) primordial $(\bullet)$ and primary $(\diamond)$ follicles, and (c) secondary $(\boldsymbol{\Lambda}$ and early antral $(\nabla)$ follicles.

and between day 159 and day 184, serum FSH was significantly higher than that between day 120 and day 150 $(P<0.05)$. Serum FSH increased between day 120 and day 159 in the bovine fetus.

\section{Serum concentration of oestradiol}

The serum concentration of oestradiol was $13.4 \pm 6.1$ $\mathrm{pg} \mathrm{ml}^{-1}$ in four fetuses from day 59 to day 149 (Fig. 4). In these four fetuses, the serum concentrations of oestradiol from day 59 to day 117 and from day 118 to day 149 were 

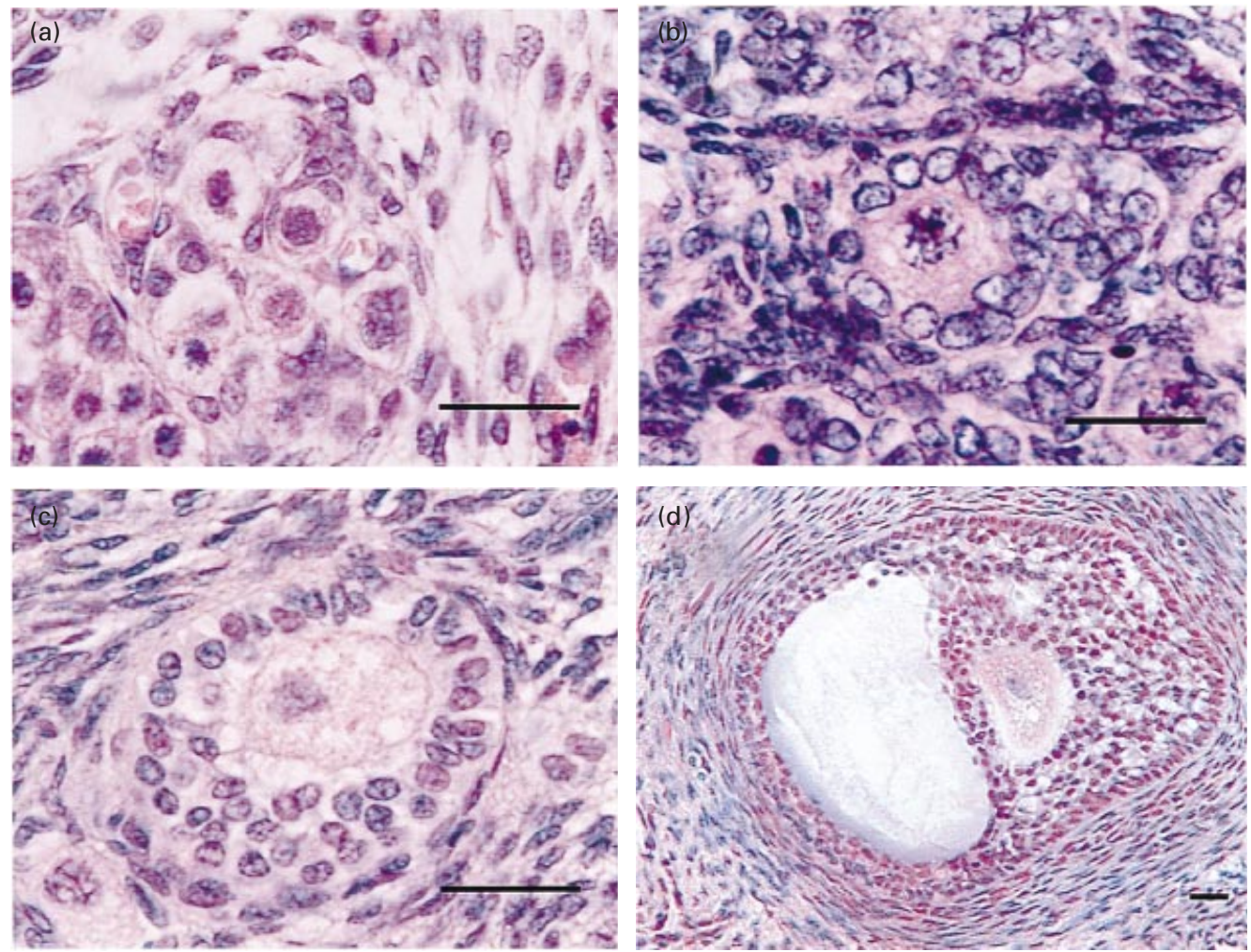

Fig. 3. Photomicrograph of haematoxylin-eosin-stained sections of bovine fetal ovaries. (a) Primordial follicles at day 74, (b) primary follicles at day 91, (c) secondary follicles at day 120 and (d) early antral follicle at day 150 . Scale bars represent $20 \mu \mathrm{m}$.

$4.6 \pm 2.6 \mathrm{pg} \mathrm{ml}^{-1}$ and $22.3 \pm 1.8 \mathrm{pg} \mathrm{ml}^{-1}$, respectively. Serum oestradiol increased from day 120, when the increase in serum FSH was initiated. The serum concentration of oestradiol was $64.1 \pm 8.8 \mathrm{pg} \mathrm{ml}^{-1}$ from day 150 to day 184 , and $78.3 \pm 11.9 \mathrm{pg} \mathrm{ml}^{-1}$ from day 186 to day 270 , when the number of early antral follicles was increasing. The serum concentrations of oestradiol from day 150 to day 184 and from day 186 to day 270 were significantly higher compared with those between day 59 and day $149(P<0.05)$. Serum concentrations of oestradiol increased during mid-gestation $(P<0.01)$.

\section{Fetal ovarian contents of oestradiol}

The content of oestradiol in the fetal ovaries was $30.8 \pm 5.1$ pg per ovary from day 59 to day 117 (Fig. 4) and $23.8 \pm 6.1 \mathrm{pg}$ per ovary from day 118 to day 149 . The content of oestradiol was $47.5 \pm 9.6$ pg per ovary from day 150 to day 184 , when early antral follicles appeared but were not increasing in number and was $106.5 \pm 25.2 \mathrm{pg}$ per ovary from day 186 to day 270, when the number of early antral follicles was increasing. The ovarian oestradiol content from day 186 to day 285 was significantly higher than that from day 59 to day 117 and from day 118 to day $149(P<0.05)$. The content of oestradiol increased during late gestation.

\section{Discussion}

In the present study, fetal ovarian mass increased markedly after day 180 of gestation, as also reported by Erickson (1966). The increase in ovarian mass after day 180 may be associated with the development of follicles.

In the present study, the first appearance of primordial, primary, secondary and early antral follicles occurred at an earlier stage than that reported by Rüsse (1983). The reason for this difference has not been established. Serum FSH in the female bovine fetus increased between day 120 and day 150 of gestation. This increase in FSH was associated with the appearance of follicles in the fetal ovary. However, primordial follicles appeared in fetuses at day 74 of gestation, and the number of follicles increased before an increase in serum FSH. The mechanism by which the development of primordial follicles is controlled has not been elucidated. However, findings from the present study indicate that the serum concentration of $\mathrm{FSH}$ is not associated with the appearance of primordial follicles.

Primary follicles were observed in the bovine fetus before the increase in the concentration of serum FSH. Bao et al. (1997) reported that $\mathrm{FSH}$ receptors are present on granulosa cells in some primary follicles in cows; therefore, primary follicles may be able of respond to a low concentration of FSH. The appearance of primary follicles 
(a)

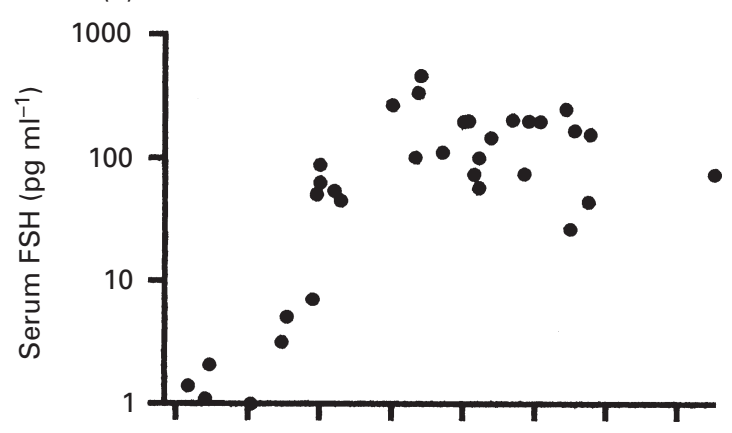

(b)

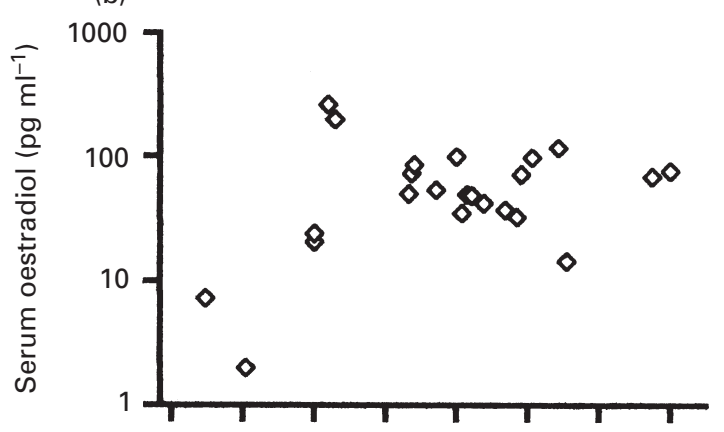

(c)

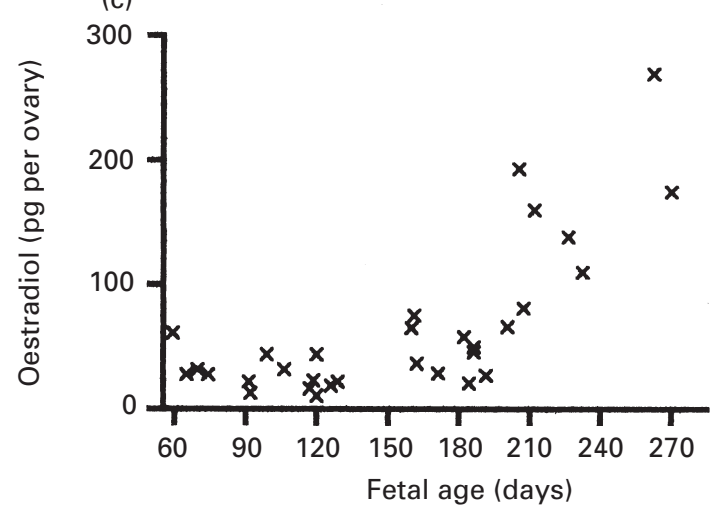

Fig. 4. Changes in serum concentrations of (a) $\mathrm{FSH}\left(\bullet, \mathrm{pg} \mathrm{ml}^{-1}\right)$ and (b) oestradiol $\left(\diamond, \mathrm{pg} \mathrm{ml}^{-1}\right)$ in the bovine fetus, and contents of (c) oestradiol ( $\times$, pg per ovary) in the bovine fetal ovary.

at day 91 was not associated with an increase in oestradiol (in the ovary or the serum content). However, George and Ojeda (1987) reported that vasoactive intestinal peptide enhanced the activity of aromatase in primary follicles of the neonatal rat ovary before the follicles had become responsive to $\mathrm{FSH}$. In the present study, it was not determined whether primary follicles have the ability to synthesize oestradiol.

The appearance of secondary follicles at day 120 was associated with an increase in serum FSH. Bao et al. (1997) reported the presence of $\mathrm{FSH}$ receptors on the granulosa cells in secondary and antral follicles. In the present study, the increase in the concentration of FSH at day 120 coincided with the development of primary follicles to secondary follicles. During the period when the number of secondary follicles increased (days 120-150), the serum concentration of oestradiol increased. This finding is supported by similar studies that report increased concentrations of circulating FSH and oestradiol in the ovine fetus with the appearance of secondary follicles (Findlay and Seamark, 1973; Sklar et al., 1981).

Angiogenesis in the adult ovary is closely related to folliculogenesis in the ovary (Lee et al., 1999). Angiogenesis and vasodilation, which were observed around secondary follicles, may be capable of improving the access of FSH to the follicles and release of oestradiol from the follicles in the fetal ovary. The distribution of blood vessels around secondary follicles may be related to growth from secondary follicles to early antral follicles.

Higher concentrations of serum FSH were observed at day 150 when early antral follicles appeared than at day 120. Oestradiol stimulates the proliferation of granulosa cells and formation of the antrum (Peters and McNatty, 1980). The increase in the ovarian content of oestradiol from day 180 was associated with an increase in the number of early antral follicles. In addition, an increase in the number of early antral follicles may coincide with an accumulation of oestradiol in the antrum.

Changes in the maternal plasma concentrations of oestradiol and FSH during gestation have been reported (Fairclough et al., 1976; Schallenberger et al., 1985). Maternal concentrations of oestradiol were $<100 \mathrm{pg} \mathrm{ml}^{-1}$ up to day 270 of gestation and $>100 \mathrm{pg} \mathrm{m}^{-1}$ from day 270 of gestation to term. No significant changes in maternal concentrations of FSH were observed throughout gestation. Therefore, the pattern of changes in fetal concentrations of FSH and oestradiol are different from the pattern of changes in maternal concentrations.

In summary, FSH may play an important role as an initiator of early follicular development in the bovine fetal ovary. Oestradiol may be produced in the secondary and early antral follicles of the fetus as also shown in cows. The growth of these follicles may be accompanied by the development of blood vessels around the follicles. These findings indicate that folliculogenesis in the bovine fetus during gestation may be stimulated by $\mathrm{FSH}$, which stimulates oestrogen in the follicles of the bovine fetal ovary after day 120, and by the development of blood vessels around the follicles, which contain oestradiol in the antrum after day 180. The development of blood vessels may be dependent on the concentration of oestradiol released around the vessels.

\section{References}

Bao B and Garverick HA (1998) Expression of steroidogenic enzyme and gonadotropin receptor genes in bovine follicles during ovarian follicular waves: a review Journal of Animal Science 76 1903-1921

Bao B, Garverick HA, Smith GW, Smith MF, Salfen BE and Youngquist RS (1997) Changes in mRNA encoding LH receptor, cytochrome P450 side chain cleavage and aromatase are associated with recruitment and selection of bovine ovarian follicles Biology of Reproduction 56 1158-1168

Bolt DJ and Rollins R (1988) Development and application of a radio- 
immunoassay for bovine follicle-stimulating hormone Journal of Animal Science 56 146-154

Erickson BH (1966) Development and radio-response of the prenatal bovine ovary Journal of Reproduction and Fertility 10 97-105

Erickson GF and Danforth DR (1995) Ovarian control of follicle development American Journal of Obstetrics and Gynecology 172 736-747

Evans HE and Sack WO (1973) Prenatal development of domestic and laboratory mammals - growth curves, external features and selected references Anatomical Histology Embryology 2 11-45

Fairclough RJ, Hunter JT, Welch RAS, Barr H and Seamark RF (1976) Preparturient changes in plasma concentrations of estrone, oestradiol$17 \alpha$ and oestradiol-17 $\beta$ in the fetal calf, effects of dexamethasone infusion Steroids 28 881-888

Findlay JK and Seamark RF (1973) The occurrence and metabolism of oestrogens in the sheep foetus and placenta The Endocrinology of Pregnancy and Parturition - Experimental Studies in the Sheep 54-64

George FW and Ojeda SR (1987) Vasoactive intestinal peptide enhances aromatase activity in the neonatal rat ovary before development of primary follicles or responsiveness to follicle-stimulating hormone Proceedings National Academy of Sciences USA 84 5803-5807

Korenman SG, Stevens RH, Carpenter LA, Robb M, Niswender GD and Sherman BM (1974) Estradiol radioimmunoassay without chromatography: procedure, validation and normal values Journal of Clinical Endocrinology and Metabolism 38 718-720

Lee HS, Lee I-S, Kang T-C, Jeong G-B and Chang S-B (1999) Angiogenin is involved in morphological changes and angiogenesis in the ovary Biochemical and Biophysical Research Communications 257 182-186

McNatty KP, Smith P, Hudson NL, Heath DA, Tisdall DJ, O W-S and
Braw-Tal R (1995) Development of the sheep ovary during fetal and early neonatal life and the effect of fecundity genes Journal of Reproduction and Fertility Supplement 49 123-135

Mueller PL, Sklar CA, Gluckman PD, Kaplan SL and Grumbach MM (1981) Hormone ontogeny in the ovine fetus. IX. Luteinizing hormone and follicle-stimulating hormone response to luteinizing hormone-releasing factor in mid- and late gestation and in the neonate Endocrinology $\mathbf{1 0 8}$ $881-886$

Peters H and McNatty KP (1980) The Ovary. In Reproductive Biology Handbooks 175 pp Ed. P Elek. Granada Press, New York

Rüsse I (1983) Oogenesis in cattle and sheep Bibliotheca Anatomica 24 77-92

Schallenberger E, Rampp J and Walters DL (1985) Gonadotrophins and ovarian steroids in cattle. II. Pulsatile changes of concentrations in the jugular vein throughout pregnancy Acta Endocrinologica 108 322-330

Sklar CA, Mueller PL, Gluckman PD, Kaplan SL and Rudolph AM (1981) Hormone ontogeny in the ovine fetus. VII. Circulating luteinizing hormone and follicle-stimulating hormone in mid- and late gestation Endocrinology 108 874-880

Taya K, Watanabe G and Sasamoto S (1985) Radioimmunoassay for progestrerone, testosterone and estradiol- $17 \beta^{125}$ I-iodohistamine radioligands Japanese Journal of Animal Reproduction 31 186-197

Received 18 September 2000

First decision 10 November 2000.

Accepted 4 January 2001 